\title{
PENGARUH LESITIN DALAM PAKAN TERHADAP PEMATANGAN GONAD DAN PEMIJAHAN UDANG PUTIH (Penaeus indicus) ASAL TAMBAK INTENSIF
}

\author{
Ketut Suwirya*), M. Marzuqi $i^{*}$ dan Haryanti*)
}

\begin{abstract}
ABSTRAK
Percobaan ini dilakukan untuk mengetahui pengaruh lesitin dalam pakan pada pematangan gonad dan pemijahan udang putih, Penaeus indicus yang berasal dari tambak intensif. Udang putih betina yang mempunyai bobot $18-25 \mathrm{~g}$ diberi pakan dengan kandungan lesitin $1,50 \%$ (A), $3,00 \%(B), 4,50 \%$ (C) dan $0,00 \%$ (D) selama 75 hari.
\end{abstract}

Dari hasil percobaan terlihat bahwa udang putih yang diberi pakan A (lesitin 1,50\%) mempunyai indeks kematangan gonad 2,54\%, produksi telur/ind. 28.814 dan daya tetas telur yang terbaik (43,46\%). Peningkatan kadar lesitin dalam pakan $>1,50 \%$ ternyata menurunkan indeks kematangan telur, produksi telur dan daya tetas telur, yakni pada pakan B berturut-turut 1,49\%, 14.004 dan $18,93 \%$ dan pada pakan $\mathrm{C}$ berturut-turut $1,43 \%, 15.430$ dan $21,59 \%$.

\section{ABSTRACT: Effect of Dietary Lecithin on Gonadal Maturation and Spawning of White Shrimp, Penaeus indicus Broodstock from Intensive Culture Pond. By: Ketut Suwirya, M. Marzuqi and Haryanti.}

The experiment was conducted to find out the effect of dietary lecithin on gonadal maturation and spawning of white shrimp, Penaeus indicus from intensive culture pond. The female weighing $18.25 \mathrm{~g}$ were fed with experimental diets containing lecithin of $1.50 \%(\mathrm{~A}), 3.00 \%(\mathrm{~B}), 4.50 \%(\mathrm{C})$ and $0.00 \%$ (D) for 75 days rearing.

The result of experiment indicated that the white shrimp fed with diet A (lecithin $1.50 \%$ ) had highest gonadosomatic index (2.54\%), eggs production/ind. (28.814) and hatching rate (43.46\%). Increasing the level of lecithin on diets $>1.50 \%$ reduced the gonadosomatic index, egg production, as well as egg hatching rate up to $1.49 \%, 14.004$ and $18.93 \%$ for diet B and $1.43 \%, 15.430$ and $21.59 \%$ for diet $\mathrm{C}$ respectively.

\section{KEYWORDS: Lecithin, gonadal maturation, Penaeus indicus.}

\section{PENDAHULUAN}

Saat ini pembenihan udang masih banyak menggunakan induk udang dari alam, baik udang windu (Penaeus monodon) maupun udang putih (Penaeus indicus). Untuk mengantisipasi perkembangan pembenihan dan pemanfaatan induk tersebut maka perlu diteliti penggunaan induk dari hasil budidaya. Induk udang dari alam sangat bergantung pada musim, jumlah yang terbatas dan harga yang cukup mahal. Di samping itu, penggunaan induk alam secara terus menerus akan berakibat penurunan sumber daya karena terjadinya penangkapan yang berlebih. Di Indonesia masih belum banyak digunakan induk udang asal tambak, namun penelitian ke arah tersebut sudah beberapa kali dilakukan khusus. nya udang windu pada Lolitkanta Gondol (Ruchimat et al., 1992; Jufri et al., 1993. Untuk memperoleh calon induk udang tambak mutu baik, perlu diketahui jenis pakan yang berpengaruh terhadap pematangan gonad dan kesehatannya.

Komposisi pakan yang khusus merupakan salah satu faktor yang dapat mempengaruhi laju perkembangan gonad udang (Primavera, 1985). Fosfolipid memegang peranan penting dalam fisiologi krustase khususnya lesitin. Lesitin berperan dalam transportasi lemak dan kholesterol

Peneliti pada Loka Penelitian Perikanan Pantai Gondol, Bali. 
antar organ serta berperan sebagai pemacu pertumbuhan. Kemampuan udang untuk mensintesis lesitin sangat rendah sehingga diperlukan dalam pakan untuk menunjang pertumbuhan (D Abramo et al., 1982).

Lemak pakan merupakan sumber energi, asam lemak esensial dan fospolipid untuk pertumbuhannya (Kanazawa et al., 1979 dan Kanazawa, 1992). Komposisi dan jumlahnya dalam pakan diduga mempunyai peranan penting dalam proses perkembangan gonad udang.

Dari permasalahan di atas terlihat perlunya mengetahui kadar lesitin dalam pakan induk udang putih untuk memacu perkembangan gonad. Hasil ini diharapkan dapat digunakan untuk meningkatkan kualitas induk udang putih asal tambak.

\section{BAHAN DAN METODE}

Dalam percobaan ini digunakan induk udang putih yang telah dipelihara di tambak selama 110 hari dan mempunyai ukuran 18-25 g untuk betina dan jantan 16-21 g untuk jantan. Selama percobaan induk tersebut dipelihara dalam bak ukuran $3,75 \times 3,75 \times 1,20 \mathrm{~m}^{3}$ dan dasar pasir dengan sistem dasar ganda. Kepadatan induk adalah 20 ekor betina dan 20 ekor jantan dalam setiap bak. Setiap individu induk betina di-beri nomor untuk mengetahui perkembangan bobot dan gonad selama percobaan.

Sebelum percobaan dimulai calon induk udang putih tambak diadaptasikan dengan kondisi laboratorium dan pakan buatan selama 7 hari setelah itu baru dimasukkan ke dalam bak-bak percobaan. Pemeliharaan induk ini dalam bakbak percobaan menggunakan air dengan pergantian sebanyak $50 \%$ per hari. Jumlah pakan yang diberikan per hari adalah $3 \%$ bobot udang.

Percobaan ini mengunakan rancangan acak lengkap dengan melihat individu sebagai ulangan. Kadar lesitin dalam pakan adalah 0,00\%, $1,50 \%, 3,00 \%$ dan 4,50\%. Untuk menyeimbangkan kadar energi yang bersumber dari lemak, ditambahkan minyak hati cumi dengan kadar yang disesuaikan dengan kadar lesitin yang diberikan sehingga formulasi pakan percobaan menjadi seperti tertera pada Table 1.

Table 1. Formulation of experimental diets.

\begin{tabular}{|c|c|c|c|c|}
\hline \multirow{2}{*}{$\begin{array}{c}\text { Ingredients } \\
(\%)\end{array}$} & \multicolumn{4}{|c|}{ Diets (\%) } \\
\hline & $\boldsymbol{A}$ & $\boldsymbol{B}$ & $C$ & $D$ \\
\hline Casein & 10.00 & 10.00 & 10.00 & 10.00 \\
\hline Fish meal & 20.00 & 20.00 & 20.00 & 20.00 \\
\hline Squid meal & 13.00 & 13.00 & 13.00 & 13.00 \\
\hline Shrimp meal & 16.00 & 16.00 & 16.00 & 16.00 \\
\hline Cholesterol & 1.00 & 1.00 & 1.00 & 1.00 \\
\hline Vit. mix. & 2.05 & 2.05 & 2.05 & 2.05 \\
\hline Mineral mix. & 8.00 & 8.00 & 8.00 & 8.00 \\
\hline Dextrin & 3.00 & 3.00 & 3.00 & 3.00 \\
\hline Sucrose & 9.00 & 9.00 & 9.00 & 9.00 \\
\hline$\alpha$-starch & 2.45 & 2.45 & 2.45 & 2.45 \\
\hline Gluten & 8.00 & 8.00 & 8.00 & 8.00 \\
\hline Lecithin & 1.50 & 3.00 & 4.50 & 0.00 \\
\hline Squid liver oil & 5.50 & 4.00 & 2.50 & 7.00 \\
\hline Total & 100.00 & 100.00 & 100.00 & 100.00 \\
\hline
\end{tabular}


Percobaan ini berlangsung selama 75 hari dan ablasi dilakukan pada hari ke 60. Sepuluh hari setelah ablasi diambil 8 ekor induk betina dari masing-masing perlakuan untuk pengamatan indeks gonad somatik (GSI) dan indeks hepatopankreas somatik (HSI), sedangkan sisanya dibiarkan sampai bertelur. Dari data ini diketahui jumlah telur per individu yang dihasilkan dan daya tetasnya dari masing-masing perlakuan. Data yang diperoleh diuji dengan uji F. Selanjutnya diteruskan dengan LSD untuk melihat perlakuan yang terbaik.

\section{HASIL DAN PEMBAHASAN}

Selama percobaan ternyata udang putih pada masing-masing perlakuan mengalami pertumbuhan rata-rata $24,37-28,27 \%$, namun dari uji $\mathrm{F}$ dapat dikatakan bahwa lesitin tidak berpengaruh terhadap pertumbuhan induk udang putih. Walaupun demikian, perkembangan gonad induk udang putih tambak dipengaruhi oleh kadar lesitin dalam pakan. Hal ini dapat dilihat dari indeks gonad somatik (GSI) dari setiap perlakuan pada Table 2. Kadar lesitin pakan 1,50\% memberikan GSI yang tertinggi, yaitu 2,54\%, sedang peningkatan kadar lesitin pakan menjadi $3,00 \%$ dan $4,50 \%$ dengan menurunkan kadar minyak hati cumi menjadi $4,00 \%$ dan $2,50 \%$, justru menyebabkan penurunan GSI, yaitu masing-masing $1,49 \%$ dan $1,43 \%(P>0,05)$.

Pada Table 2 juga terlihat bahwa penambahan lesitin dalam pakan sebanyak $1,50 \%$ menyebabkan HSI yang terbaik. Hal ini memperlihatkan bahwa lesitin berfungsi dalam transportasi lemak dan kholesterol ke hepatopankreas dan selanjutnya diteruskan ke gonad.

Table 2. Growth, GSI, HSI, egg productions/ind and hatching rate of white shrimp after 75 days rearing.

\begin{tabular}{lccccc}
\hline \multirow{2}{*}{ Parameters } & & \multicolumn{4}{c}{ Lecithin in the diets } \\
\cline { 3 - 6 } & & $\mathbf{A}(\mathbf{1 , 5 0 \% )}$ & $\mathbf{B}(\mathbf{3 , 0 0 \% )}$ & $\mathbf{C}(\mathbf{4 , 5 0 \% )}$ & $\mathbf{D}(\mathbf{0 , 0 0 \% )}$ \\
\hline \multirow{2}{*}{ Growth } & $(\%)$ & $28.27^{\prime}$ & $24.27^{a}$ & $24.46^{a}$ & $25.07^{a}$ \\
GSI & $(\%)$ & $2.54^{b}$ & $1.49^{a}$ & $1.43^{a}$ & $1.43^{a}$ \\
HSI & $(\%)$ & $3.97^{\circ}$ & $3.16^{a}$ & $3.27^{a}$ & $3.48^{a}$ \\
Egg production/ind. & & $28.814^{\circ}$ & $14.004^{a}$ & $15.430^{a b}$ & $21.747^{\circ c}$ \\
Hatching rate & $(\%)$ & $43.46^{b}$ & $18.93^{a}$ & $21.59^{a}$ & $24.89^{a}$ \\
\hline
\end{tabular}

" Values ini rows followed by similar superscript were not significantly different $(P>0.05)$.

Keterkaitan antara GSI dan HSI seperti terlihat pada Table 2, bahwa pada kadar lesitin $1,50 \%$ dalam pakan akan menyebabkan fungsi hati maksimum (HSI paling tinggi) dan kematangan paling cepat (GSI paling tinggi). Kadar lesitin pakan optimum akan menyebabkan GSI dan HSI maksimum. Penurunan atau kenaikan dari kadar tersebut akan menyebabkan menurunnya GSI dan HSI.

Dalam percobaan ini minyak hati cumi merupakan sumber energi dan HUFA n-3, namun dengan pengurangan minyak hati cumi $1,50 \%$ $3,00 \%$ pada penggunaan kadar lesitin $>1,50 \%$ akan menyebabkan penurunan GSI dan HSI
(Table 2). Jadi pakan induk udang putih asal tambak yang baik dalam percobaan ini adalah yang mengandung $5,50 \%$ minyak hati cumi dan $1,50 \%$ lesitin.

Produksi telur per individu juga cenderung meningkat dengan penambahan lesitin 1,50\% dalam pakan, namun tidak berbeda nyata dengan tanpa penambahan lesitin dalam pakan. Penambahan lesitin $3,00 \%$ dan $4,50 \%$ dalam pakan menghasilkan jumlah telur per individu yang lebih rendah (Table 2). Dari hasil percobaan ini tampaknya ada keterkaitan antara kandungan lesitin dan minyak hati cumi dalam pakan. Oleh karena itu, untuk melihat pengaruh lesitin 
secara tersendiri dalam pakan seharusnya digunakan kadar minyak hati cumi yang sama. Untuk penyeimbang energi dapat digunakan sumber lemak yang tidak mengandung asam lemak esensial seperti asam lemak oleat (16:0).

Beberapa penelitian menunjukkan bahwa pematangan gonad dan pemijahan dipengaruhi oleh kandungan lesitin dalam pakan untuk udang $P$. setiferus sebesar 3,00\% (Lawrence et al., 1979; Midleditch et al., 1980), dan P. japonicus sebesar 3,00\% (Teshima dan Kanazawa, 1983; Teshima et al., 1989, Alava et al., 1993).

\section{KESIMPULAN}

Kandungan lesitin sebesar 1,50\% dalam pakan induk udang putih dapat mempercepat pematangan gonad dan meningkatkan daya tetas telur yang dihasilkan. Namun hasil ini juga dipengaruhi oleh kadar minyak hati cumi yang ditambah dalam pakan, sehingga penambahan lesitin harus mempertimbangkan dengan cermat jenis dan komposisi bahan-bahan penyusun yang lain.

\section{DAFTAR PUSTAKA}

Alava, V.R., A. Kanazawa, S. Teshima, and S. Koshio. 1993. Effect of dietary phospolipid and n-3 highly unsaturated fatty acids on ovarion development of kuruma prawn. Bull.Jap.Soc. Sci.Fish. 59:345-351.

D'Abramo, L.R., C.E. Conclin and N. Baum. 1981. Essentiality of dietary phospati-dylcholin for the survival of juvenile lobsters. J. Nutr. 111: 425-431.

Jufri, M. Marzuqi, N. A. Giri dan C. Kuma. 1993. Pengaruh penambahan vitamin $\mathrm{E}$ terhadap perkembangan gonad udang windu, $P$. monodon asal tambak. J. Penelit. Budidaya Pantai, Maros. 9(2): 127-126.

Kanazawa, A., S. Teshima and M. Ondo. 1979. Requirement of prawn, $P$. japonicus for essential fatty acid. Mem. Fac. Fish., Kagoshima Univ.. 28:27-33.

Kanazawa, A. 1992. Recent advances in penaeid nutrition in Japan. In G.L. Allan and W. Dall (Eds) Proc. Aquacult. Nutrition Workshop, Australia.

Lawrence,A.L., D. Ward, S. Missler, A. Brown, J. McVey and B.S. Midleditch. 1979. Organ indices and biochemical levels of ova from penaeid shrimp maintained in captivity versus those captured in wild. Proccedings of the World Maricult. Sci., 10:453-463.

Middledith, B.S., S.R. Missler, H.B. Hines, J.P. McVey, A. Brown, D.G. Ward and A.L. Lawrence. 1980. Metabolic profiles of penaeid shrimp: dietary lipids and ovarian maturation. Journal of Chromatography. 195: 359-368.

Primavera, J.P.. 1985. A review of maturation and reproduction in penaeid. p.47-64. Proc. First Inter. Conf. Cult. Penaeid prawn/shrimp. Iloilo city. Philippines.

Ruchimat, T., Trijoko, T. Sutarmat dan S. Lante. 1992. Pematangan ovari udang windu dengan penyuntikan ekstrak torasik ganglion lobster. J. Penel. Budidaya Pantai. 8(3): 9-14.

Teshima, S. and A. Kanazawa. 1983. Variation in lipid composition during the ovarian maturation of the prawn. Bull. Jpn. Soc. Fish. 957-962.

Teshima, S., S. Koshio and K. Horinouchi. 1989. Lipid metabolism of the prawn $P$. japonicus during maturation: variation in lipid profile of the ovary and hepatopancreas. Comp. Biochem. Physiol., 92: 45-49. 